\title{
Cuidado y autocuidado en el personal de salud: enfrentando la pandemia COVID-19
}

\section{Facing the pandemic COVID-19: Care and self-care in health personnel}

Patricia Macaya B. ${ }^{1}$, Fernando Aranda G. ${ }^{2}$

\begin{abstract}
The great global and regional changes, both political, social and health, have created a situation of uncertainty for all people. In particular, health personnel have been very stressed in this coronavirus pandemic. We present this review with the aim of collaborating in the understanding and containment of our colleagues in health personnel.

\section{RESUMEN}

Los grandes cambios mundiales y regionales, tanto políticos, sociales y sanitarios, han generado una situación de incertidumbre en todas las personas. Particularmente el personal de salud se ha visto muy estresado, en esta pandemia del coronavirus. Presentamos esta revisión con el objetivo de colaborar en la comprensión y contención de nuestros colegas del personal de salud.
\end{abstract}

\section{Key words:}

Burnout syndrome, crisis, self care

\section{Palabras clave:}

Síndrome Burnout, crisis, autocuidado
Y a desde fines del año 2019 a raíz del movimiento social en Chile, estábamos viviendo un periodo de incertidumbre. Luego, iniciamos el año 2020 con el conocimiento, pero no siendo conscientes del peso que tendrían dos hechos que impactarían nuestra percepción y enfrentamiento de los desafíos de la práctica clínica diaria. Nuevo año, nueva crisis, nueva oportunidad de crecimiento:

- El síndrome de Burnout (desgaste profesional) a nivel global, en el personal de salud y profesionales médicos de variadas especialidades. 20182019.

- La neumonía viral COVID-19, en Wuhan, China. Diciembre de 2019.

Anestesióloga, Hospital FACH, Universidad de Valparaíso. Valparaíso, Chile.

Anestesiólogo, Hospital Dr. Gustavo Fricke, Universidad de Valparaíso. Valparaíso, Chile.

Fecha de recepción: 15 de abril de 2020

Fecha de aceptación: 16 de abril de 2020

\section{ORCID}

https://orcid.org/0000-0003-3478-5988

Correspondencia:

Fernando Aranda G.

Email: aranda.fernando@gmail.com 
Tanto como profesionales presentes en la primera línea en los servicios en Anestesia como en los Cuidados Intensivos, así como líderes y referentes de equipos de trabajo, nos estamos viendo enfrentados a una crisis sanitaria mundial, junto a una sobreexigencia de nuestro sistema de salud, lo cual nos impone desarrollar mecanismos de adaptación, optimización de recursos y de medidas de autocuidado que comprendan a todo el equipo de salud[1].

Así, por estas razones, es que nos hemos propuesto realizar una revisión de la literatura con el fin de identificar aspectos que nos permitan proteger al personal de salud durante esta gran crisis.

La incertidumbre, el estrés que conlleva las dificultades en la atención médica durante un brote epidémico como coronavirus (COVID-19), exige una especial atención a las necesidades de apoyo emocional del personal de salud. Cuidarse a sí mismo y animar a otros a autocuidarse mantiene la capacidad de cuidar a los pacientes (Sociedad Española de Psiquiatría).

Debemos enfocarnos como equipo a disminuir y tratar de evitar las consecuencias de situaciones de estrés crónico mal o no manejado, ya que responder a la situación aguda con alerta y eficiencia no es sostenible en el tiempo y el costo personal es muy alto en el largo plazo. La experiencia clínica y estudios han evidenciado que el estrés, trauma y la represión de emociones son capaces de causar dolor y otros síntomas físicos que se han correlacionado a variadas entidades clínicas. Por otro lado, se propicia la manifestación y/o descompensación de patologías subyacentes.

\section{Síndrome de Burnout: (ICD-11) mayo de 2019[2]-[4]}

El Burnout ha sido mencionado como materia de preocupación en la literatura desde la década de los años 70; sin embargo, no fue recocido como una entidad particular relacionada al trabajo hasta el año recién pasado.

Es un síndrome que considera tres dimensiones:

- Sensación de falta de energía y agotamiento.

- Distanciamiento mental progresivo en el trabajo, percepción negativa del entorno, cinismo.

- Disminución de la eficiencia profesional.

En la encuesta 2018 de práctica médica en EE. UU. se reportó un sorprendente $78 \%$ de Burnout, siendo un 4\% mayor que el año 2016. En la encuesta 2019 de la Asociación Médica Británica se reportó un 80\% de profesionales en riesgo. Así, paulatinamente, el Burnout se ha llegado a considerar un problema de Salud Pública, ya que no solo afecta a la vida personal y la satisfacción laboral de los profesionales, sino que, además, crea una severa presión para el sistema de salud y seguridad de los pacientes.

A pesar de que los estudios se han hecho en países desarrollados, el Burnout es un problema y una epidemia escondida en países en vías de desarrollo, dada la gran demanda asistencial que representan estos servicios de salud.

\section{La neumonía viral COVID-19 (SRAS-CoV2)[5]-[8]}

Los primeros reportes de una nueva neumonía, en la ciudad de Wuhan, provincia de Hubei, China, fueron hechos a fines de diciembre de 2019, desatando un rápido aumento en el número de casos y de contagios a nivel global; el virus aislado, fue inicialmente designado como SARS-CoV2 y la OMS le dio su nombre COVID-19 el 12 de febrero de 2020, siendo declarada la pandemia por la OMS por SARS-CoV2 el 11 de marzo de 2020. En Chile el primer caso fue reportado el 3 de marzo de 2020.

El brote COVID-19 es un estrés importante para todo el personal de salud, ya que la gran mayoría es de primera línea en su atención.

Ahora, más que nunca, es importante que el sistema y las organizaciones proveedoras de salud creen y aseguren una estructura de recursos para apoyar a médicos, enfermeras y miembros del equipo.

En el corto plazo y enfrentando la realidad actual, el personal de salud está tratando de balancear lo mejor posible sus competencias profesionales, con los cuidados de los pacientes, sus familias y el propio cuidado.

En la actualidad, la situación de crisis inducida por la pandemia por COVID-19, está causando un enorme desgaste adicional en los sistemas de salud a nivel mundial, entendido como personas, instituciones y proveedores. $Y$ si bien, nos informamos y actualizamos el conocimiento, tanto individualmente como en equipo, estamos sujetos a una gran cantidad y diversidad de información, creando un ambiente de inseguridad y angustia dentro de los equipos de trabajo.

Somos testigos de la dura realidad y de la experiencia de aquellos países que nos llevan semanas de ventaja en la evolución de esta pandemia; así como, de lo que va ocurriendo en las distintas regiones de nuestro extenso país. 


\section{¿Qué pasa con las personas?, ¿qué pasa con el equipo de salud? El autocuidado en tiempos de crisis.}

Existen muchas definiciones de crisis.

- Slaikeau (1984): “Es un estado temporal de trastorno y desorganización, caracterizado principalmente por la incapacidad del individuo para abordar situaciones particulares utilizando los métodos acostumbrados para la resolución de problemas".

- L. R Brito: "La crisis se siente como un abismo entre el pasado que ya no es vigente y un futuro que aún no está constituido".

- Jerry Long Jr.: "La persona está en crisis cuando sufre una pérdida severa que no está manejando exitosamente y siente ira sublimada, está estancada en la fase de depresión y sufriendo un vacío existencial".

Las respuestas del individuo a la crisis se pueden categorizar de la siguiente forma:

Nivel cognitivo: Se produce un desborde de las habilidades de resolución de los problemas y de los mecanismos de enfrentamiento usuales (confusión, bloqueo de pensamiento, pensamiento dicotómico, catastrófico, rigidez, etc.).

Nivel emocional: Se expresa angustia, shock, temor, terror, tristeza, aplanamiento, incredulidad, inquietud, excitabilidad, entre otros.

Nivel fisiológico: Aparecen signos de estrés general, alteración del sueño y apetito, taquicardia, sudoración, dolor físico, etc.

Los estudios coinciden en que toda crisis conlleva peligro y oportunidad: por lo que casi siempre será necesaria una intervención, la cual podría hacer una diferencia en las decisiones que tome el individuo en crisis.

\section{Intervención en crisis (Slaikeau)[9]}

Es el proceso de ayuda dirigido a auxiliar a una persona o grupo para soportar un proceso traumáti$\mathrm{CO}$, de modo que la probabilidad de efectos negativos como daños físicos, psicológicos o emocionales, que pueden ocurrir en el momento del suceso o posteriormente, se aminoren y la probabilidad de crecimiento se incremente.

Se caracteriza por ser inmediata y realizada en el lugar del suceso, breve y usualmente única.

El objetivo principal es ayudar a recuperar el nivel de funcionamiento equilibrado que se tenía previo al evento, para poder superar el trauma. Esto se consigue reduciendo el riesgo, motivando la búsqueda de nuevos recursos y movilizando los existentes para enfrentar el futuro inmediato.

Las áreas generales de Intervención serían:

1. Establecer o facilitar la comunicación.

2. Ayudar a percibir mejor la situación.

3. Autocuidado. Ayudar en el manejo de síntomas y emociones (niveles emocional, cognitivo y conductual).

En la circunstancia actual, fomentar los espacios de trabajo como un espacio protector parece una difícil tarea. Pero el objetivo es transformar lo que se percibió como normal o como una debilidad, en una experiencia valiosa para mejorar la eficiencia, la efectividad en nuestra labor y en las relaciones interpersonales. Es decir, destacar el valor de lo conocido.

Es importante aprender a diferenciar los problemas actuales de aquellos previos a la crisis, y que son los que están creando nuestra nueva realidad.

El hecho de pertenecer a un equipo de trabajo, nos presenta la valiosa oportunidad de colectivamente, buscar y encontrar un nuevo enfrentamiento a la cambiante nueva realidad.

\section{¿Cuáles son los retos que se han identificado?}

- El alto riesgo de contagio.

- La sobrecarga en la demanda asistencial: esto dado por la consulta de pacientes relacionados a la crisis de salud, más aquellos que consultan por cuadros clínicos a los que estamos habituados, pero en carácter de descompensación o urgencia ya que se ha visto que la población evita acercarse a los recintos de salud en este periodo.

- Los elementos de protección personal (EPP): su disponibilidad, protocolos de acceso, técnicas de utilización para no incrementar el riesgo de contaminación.

- El apoyo y atención de salud al paciente y a su familia: cómo relacionarnos en este nuevo escenario.

- El estrés en las zonas de atención directa: lo que se ha llamado "la primera línea" y que incluye a profesionales de la salud y al personal de apoyo. Se puede experimentar una amplia gama de emociones (por ejemplo: pena, miedo, frustración, culpa, rabia, etc.). Se evidencia, además, una sobre-exposición al sufrimiento de familia, porque en estas circunstancias el personal de salud asume el papel de la familia frente al paciente y debe al mismo tiempo enfrentar a la familia con la entrega de información y contención.

- Dilemas éticos y morales, secundaria a la sobrecarga, restricción y/o falta de medios, incluso relacionados a la evolución del paciente. 
Como respuesta a estos retos, el personal de salud puede manifestar reacciones en el ámbito emocional, cognitivo, físico y conductual; los cuales, si se logran percibir y entender como normales frente a una situación anormal, podrían y deberían contribuir al autocuidado del mismo personal de salud (percibir la situación).

\section{Estrategias de autocuidado durante crisis COVID-19[10]-[12]}

Se presenta una fusión del enfoque psiquiátrico y psicológico, ya que ambas propuestas pueden aparecer redundantes; sin embargo, dadas las diferencias individuales en la percepción y enfrentamiento de la realidad de cada uno de nosotros y la preferencia que tengamos en el enfoque de las soluciones, es que se presenta un enfrentamiento organizado y que da la oportunidad de reflexionar como un todo personallaboral que busca soluciones y está dispuesto a pedirrecibir ayuda.

\section{Estrategias de autocuidado sugeridas}

\section{Área 1: Comunicación.}

- ¿Ansioso y/o preocupado? Un aumento en la ansiedad es absolutamente esperable, nos preocupamos por el día a día y sus consecuencias: el cuidado del paciente y su evolución, la situación financiera, el cuidado de los niños, las estrategias de organización personal, etc. Frente a esto, la acción es uno de los mejores tratamientos para la ansiedad. Por lo tanto, comparta sus preocupaciones y problemas, discuta las eventuales soluciones con sus colegas, familia y amigos. Todos se pueden beneficiar.

- Conéctese: busque el contacto no presencial con su familia, amigos y colegas. Utilice sus recursos de conectividad y redes sociales, le ayudará a sentirse menos aislado.

- Seleccione sus contactos y vías de información: éstas serán abundantes y, a veces, lo confundirá. Contraste la información obtenida con su red de contactos cercana y fuentes oficiales.

- Pida ayuda: si Ud. está a cargo del cuidado de niños y/o familiares que requieran ayuda, informe a su superior para encontrar una red de apoyo. En resumen, pida ayuda, evalúe, modifique y siga adelante.

- Póngase en el lugar de los otros: debemos aprender a empatizar con nuestro equipo de trabajo, y ellos deben darse cuenta de esta empatía.
Área 2: Percepción de la realidad.

- Infórmese: estudie los distintos aspectos que se relacionan con su trabajo cotidiano, utilizando los documentos oficiales de su institución, e idealmente, contrastarlos con la información de la literatura nacional e internacional. Usted puede aportar a la mejora de sus protocolos locales.

- Solicite información a sus jefaturas y, a su vez, mantenga informado a su equipo de trabajo.

- Participar en la elaboración de protocolos a nivel local. Esto permitirá identificar sus recursos físicos y humanos, para poder implementar mejoras acordes a su realidad. Hacer simulaciones, y repetirlas hasta que todos los integrantes del equipo de trabajo se encuentren capacitados y conformes.

- Recuerde que las soluciones a los problemas no son universales.

- Elaborar estrategias y protocolos de atención según el escenario sanitario tanto actual como futuro. Aprovechando la información de los lugares que están más avanzados dentro de la pandemia.

\section{Área 3: Autocuidado.}

- Ud. necesita tiempo: fíjese en su cantidad y calidad de sueño, su cansancio, concentración e irritabilidad. Recuerde que necesitamos cuidarnos para cuidar a nuestros pacientes, familias y comunidades.

- Respire: trate de hacer una respiración consciente varias veces en el día. Al salir de su casa, antes de entrar al hospital, antes de entrar a una sala y atender a un paciente; deténgase y respire; continúe. Respirar nos calma y ayuda a concentrarnos en la tarea.

- Mantenga hábitos saludables: a medida que el estrés y las demandas aumentan, habitualmente los buenos hábitos se debilitan. Trate de comer bien (si es posible, lleve su comida), limite la ingesta de alcohol, trate de dormir o descansar cuando pueda, haga ejercicio aeróbico (caminar), trate de exponerse al sol si es posible.

- Tome descansos cortos en el trabajo y en su casa. Con su grupo de trabajo, organícese para tomar descansos cortos, mejora su energía vital y ayuda a enfocarse en lo importante.

- Realice ejercicio aeróbico para reducir el estrés, juegue con su familia, Yoga online, por ejemplo. Recuerde, poco es mejor que nada.

- En su casa, tome tiempo para disfrutar una actividad de su preferencia: leer un libro, hacer ejercicio o compartir con su familia. Esto le ayudara a recargarse física y emocionalmente.

- Intente no llevar los problemas a casa. 


\section{¿Qué puede aportar la institución de salud en el autocuidado?[13]}

Estas son algunas iniciativas que complementarán el trabajo individual, y que se pueden resumir en:

- Incentivar el respaldo de los referentes técnicos en el liderazgo de la crisis, y al mismo tiempo, aprender a recibir aportes de manera respetuosa, considerando el bienestar de todo el recurso humano, manteniendo un buen ambiente laboral, constructivo y positivo.

- Cada uno de nosotros tiene el derecho y el deber de compartir sus apreciaciones. Sin embargo, se sugiere que se realice de manera directa y respetuosa.

- Se sugiere a las autoridades mantener los canales de comunicación abiertos con los distintos actores en esta epidemia, conservando un clima de receptividad y análisis real de las retroalimentaciones que se originen en el día a día.

- La Institución debe entregar la información clara y pertinente a sus funcionarios en relación a la cobertura de seguros laborales asociados a esta contingencia nacional. Así mismo, en relación a la necesidad o pertinencia de exámenes diagnósticos o entrega de permisos de salud.

- Se sugiere postergar las cirugías electivas con el fin de:

- Evitar la exposición innecesaria del personal de salud y de los pacientes a eventuales contagios y complicaciones.

- Permitir el recambio del personal de salud frente a eventuales contagios o períodos de cuarentena, asegurando la continuidad de la atención.

- Hacer uso racional de los recursos ya que nos enfrentamos a una carencia mundial.

- Asegurar la disponibilidad de camas de nivel intermedio e intensivo.

- Se recomienda restringir el acceso de personal y familiares al recinto hospitalario. Actualmente varios hospitales en el mundo no reciben visitas de familiares.

- Es muy conveniente elaborar un informe periódi$\mathrm{co}$, tanto institucional como de la unidad específica dirigido a todo el equipo de salud, de manera que el personal conozca el ambiente al cual se verá enfrentado al iniciar su jornada.

- Capacitar continuamente al personal en relación al COVID-19, y eventuales cambios de roles frente a la carencia futura de RR.HH.

- Concentrar los pacientes en zonas específicas para mantener el mínimo aislamiento preventivo intrahospitalario.
- Realizar ajustes de horarios de salida o entrada al recinto, en virtud de las restricciones vigentes en la zona: Toque de queda, cuarentena total, etc.

- En varios países se ha puesto a disposición recintos como hoteles, para el albergue de funcionarios de salud en períodos de descanso, y que permiten, además, mantener un distanciamiento preventivo de su grupo familiar.

- Se recomienda que exista una congruencia de instrucciones de uso de los EPP a nivel institucional, asegurando la equidad en las medidas de protección de los diferentes estamentos. Es decir, a mismo riesgo, misma protección.

- Es de alta relevancia que exista una definición de los dilemas éticos eventuales, tales como: disponibilidad de EPP, acceso a camas UCI y ventilación mecánica, definición de criterios de inclusión en ventilación mecánica, etc.

- Se recomienda ofrecer apoyo por parte de la Unidad de Psiquiatría y Psicología laboral de cada Institución, sumado al debriefing hecho por las jefaturas, realizadas en sesiones breves, permitiendo el rápido retorno del personal a sus hogares.

- Mantener un canal de Información de las estrategias a seguir por la institución, en virtud del avance de la epidemia.

- Realizar una redistribución del personal administrativo, dando preferencia al teletrabajo, concentrando este tipo de actividad en zonas que cuenten con medidas de protección personal (cubículos de trabajo protegido). Se han evidenciado renuncias del personal de salud y administrativo por un sentimiento de abandono por parte de su institución.

- Se sugiere a la institución hospitalaria coordinarse con los centros docentes, para identificar puestos o funciones claves en las cuales los alumnos de pregrado o residentes de primer año puedan proveer servicios de apoyo al personal de salud en funciones o con aislamiento preventivo, o incluso a pacientes no COVID; permitiendo que las nuevas generaciones se involucren en la crisis actual, sin comprometer su salud.

- La institución debería proveer guías para el autocuidado de su personal hacia su familia.

- Considerar el apoyo de salud mental para profesionales y sus familias, ya que la experiencia vital los afecta indirectamente.

- Conéctese con los otros, algunas instituciones han creado reuniones virtuales en que los profesionales se pueden apoyar mutuamente, compartir, discutir en lo emocional y laboral. Se considera clave el apoyo de un psicólogo en estas sesiones. 
Deje que la conversación fluya naturalmente (no se recomienda más de 15 participantes).

A continuación, se muestra un extracto de las recomendaciones que entrega el centro hospitalario Mount Sinai, basadas en las preguntas que el mismo personal de salud propuso para su autocuidado como el de sus propias familias[14]:

- ¿Qué hago cuándo llego del trabajo?

Lave cuidadosamente sus manos al entrar a su casa.

- ¿Me debo cambiar la ropa de trabajo antes de entrar a la casa?

Antes del COVID-19 ya existía la recomendación general para prevención de infecciones, que aquellos que trabajan en UCl o en relación a pabellones quirúrgicos deben cambiarse para salir del hospital. Se mantiene la recomendación.

- ¿Debo evitar a mi familia cuando estoy en casa? Si Ud. se siente bien, luego de su higiene personal, no hay razón para evitarlos. Todos deben ser conscientes de cubrirse la nariz y boca al estornudar o toser, no importa las circunstancias.

- ¿Debo evitar a las mascotas?

Siga la misma conducta de contacto que con la familia.

- ¿Qué hago si desarrollo síntomas como tos y fiebre?

Autoaíslese de los miembros de su familia en su casa (pieza separada, baño separado si es posible, sino debe limpiarse cuidadosamente después de su uso. Todos los miembros de la familia deben lavarse las manos frecuentemente, tener un manejo cuidadoso de la basura, evitar el contacto físico).

- ¿Cuánto tiempo se debe mantener el aislamiento del grupo familiar?

Al menos 14 días desde el inicio de los síntomas, evidenciando una mejoría de ellos, y sin fiebre al menos tres días.

\section{Conclusión}

La pandemia COVID-19, y esto en términos globales, está poniendo a prueba los recursos humanos, materiales y financieros de individuos, comunidades y países del mundo entero.

Esta crisis de salud sin precedentes en el mundo actual, está impactando todos los aspectos de la vida diaria como la conocemos, pero su impacto en los trabajadores de la salud es inmenso.

Aunque no todos estamos en contacto directo con estos pacientes, de una u otra manera si llevamos el peso del sistema. Todos aquellos a cargo del cuidado directo de estos enfermos, médicos, enfermeras, personal técnico y de apoyo, se convierten en su familia y soporte. El equipo de salud es la red de apoyo del paciente que está aislado y solo, lo que aumenta la carga de estrés.

Algunos trabajadores de la salud y profesionales expuestos, están en cuarentena, están físicamente aislados de sus familias, colegas y red de apoyo. Otros han elegido voluntariamente alejarse de su familia y seres queridos, tratando de evitar exponerlos de forma inadvertida.

Así, todos los involucrados, estamos viviendo un periodo de carga laboral y emocional diferente y mayor a lo que conocíamos como normal. La percepción puede aparecer como catastrófica, para el sistema y las personas involucradas, sin embargo, hay que hacer todos los esfuerzos posibles por encontrar la fortaleza y continuar.

Estamos enfrentando un periodo de crisis que está en evolución, por lo que, en todo ámbito, las recomendaciones que son válidas hoy pueden ser diferente mañana.

El cuidado Equipo de Salud como se ha presentado, trata de fomentar desde variadas perspectivas el cuidado y autocuidado de las personas involucradas en la atención de pacientes.

Diferentes recomendaciones coinciden en hacer consciente el bienestar y cuidados básicos, que quizás habíamos descuidado por considerarlos parte del "normal" que creímos garantizado.

Se enfatiza, además, la búsqueda y entrega de apoyo efectivo y emocional en diferentes instancias y en los ámbitos personal, grupo de trabajo, institución.

Institucionalmente, se propone hacer uso de las herramientas de apoyo disponibles, idealmente actividades guiadas para superar situaciones específicas que fortalezcan el enfrentamiento de la crisis a largo plazo, de manera de tratar de aminorar el impacto negativo personal y colectivo futuro. $Y$ se proponen áreas que se pueden mejorar o implementar, a saber, la empatía en el equipo de trabajo, conflictos de bioética, información de parte de la institución, salud laboral (eventual aumento de enfermedades laborales, licencias médicas, ansiedad, síndrome depresivo, en definitiva Burnout y sus consecuencias).

Todos estamos con una sobrecarga emocional y de trabajo, diferente y mayor a lo que fue nuestro normal. 
Recuerde:

- Ud. pertenece a un equipo, es su fortaleza. No está solo.

- El autocuidado es primordial: tome descansos breves a lo largo del día, camine, dentro de sus posibilidades elija una dieta equilibrada, descanse, trate de dormir. Invente una nueva rutina que lo gratifique. Solo si se cuida podrá cuidar.

- No se aísle: manténgase conectado de alguna manera a su red familiar y social.

- Su esfuerzo por ayudar a mantener la salud de otros se respeta y agradece. Sea respetuoso con sus pares y sus autoridades.

\section{Todos podemos elaborar un sentido que nos} rescate en los momentos difíciles

(V. Frankl)

Como reflexión final y recogiendo una cita de la Sociedad Española de Psiquiatría

\section{NECESITAMOS QUE TE CUIDES PARA SEGUIR} CUIDANDO Y CONTAGIAR SALUD

\section{Referencias}

1. Greenland JR, Michelow MD, Wang L, London MJ. COVID-19 Infection. Anesthesiology. Ovid Technologies (Wolters Kluwer Health); 2020 Mar;1. http://dx.doi.org/10.1097/ aln.0000000000003303.

2. CDC. Update on ICD-11.

3. WHO. Mental Health.

4. Physician burnout: a global crisis. The Lancet, Editorial| VOLUME 394,
ISSUE 10193, P93, JULY 13, 2019.

5. Virology: coronaviruses. Nature. 1968;220(5168):650. https://doi. org/10.1038/220650b0.

6. CDC, SARS.

7. Zhang $Y Z$, Holmes EC. A Genomic Perspective on the Origin and Emergence of SARS-CoV-2. Cell. 2020 Apr;181(2):223-7. https://doi. org/10.1016/j.cell.2020.03.035 PMID:32220310

8. Evan D. Kharasch, M.D., Ph.D.,
Yandong Jiang, M.D., Ph.D. Novel Coronavirus 2019 and Anesthesiology. Anesthesiology, Editorial, March 2020

9. Intervencion en Crisis. Toma de decisiones. Karl A. Slaikeu; 1998.

10. CDC. COVID-19 Stress and Coping

11. SEP COVID-19. Salud Mental personal sanitario

12. https://apaservices.org

13. https://ama-assn.org

14. https://mountsinai.org 